www.jmscr.igmpublication.org

Index Copernicus Value: 79.54

ISSN (e)-2347-176x ISSN (p) 2455-0450

crossrefDOI: https://dx.doi.org/10.18535/jmscr/v7i3.129

Journal Of Medical Science And Clinical Research

IGM Publication

An Official Publication of IGM Publication

Original Research Article

\title{
Prevalence and impact of depression and anxiety in chronic obstructive pulmonary disease: A case-control study
}

\author{
Authors \\ Dr Abdul Wahab Haji Dawood Mirza ${ }^{1}$, Dr Karan Bahadur Singh ${ }^{2 *}$, \\ Dr Naikey Minarey ${ }^{3}$
}

${ }^{1}$ Assistant Professor, Department of TB \& Chest, Index Medical College Hospital \& Research Centre, Index City, Nemawar Road, NH-59A, Indore, Madhya Pradesh 452016, India

${ }^{2}$ Associate Professor, Department of Microbiology, Index Medical College Hospital \& Research Centre, Index City, Nemawar Road, NH-59A, Indore, Madhya Pradesh 452016, India

${ }^{3}$ Assistant Professor, Department of Pediatrics, Index City, Nemawar Road, NH-59A, Indore, Madhya Pradesh 452016, India

*Corresponding Author

Dr Karan Bahadur Singh

\section{Abstract}

Background: Psychiatric morbidity has an increased prevalence in chronic obstructive pulmonary disease (COPD). Anxiety and depression are common and important comorbidities in patients with chronic obstructive pulmonary disease (COPD). We aimed to study patterns of psychosocial issues in patients with COPD.

Materials \& Methods: This is a cross-sectional pilot study that was carried out in the outpatient clinic of Chest \& TB Department, IMCHRC, Indore, M. P. About 30 COPD patients were assessed using Structured Clinical Interview for DSM IV (SCID) for establishing psychiatric diagnosis, Patient Health Questionnaire (PHQ-9) and Beck depression inventory for assessment of the severity of depressive symptoms; Hamilton anxiety scale for the severity of anxiety symptoms, and spirometry for assessing the severity of COPD and were matched to 30 healthy control subjects.

Results: In the present study 70\% of COPD patients were male. Out of 30 COPD patients 13 (43.33\%) were chronic smokers. There was family history of COPD in $33.33 \%$ and $13.33 \%$ subjects in case and control group respectively. Majority of subjects in COPD group was having depression score PHQ-9 (6-10) and (11-15) in 26.67\% respectively. Mild to moderate and moderate to severe anxiety level was observed $40 \%$ and $16.67 \%$ of COPD subjects, whereas none was noted in control group.

Conclusion: This study confirmed the high prevalence of anxiety and depression in Indian outpatients with COPD. Patients with COPD who had anxiety and/or depression had a poorer health-related quality of life. The severity of anxiety and depression were correlated with the severity of COPD. Anxious and depressive symptoms were also associated with several factors including younger age, female sex, lower household income and history of smoking.

Keywords: Chronic obstructive pulmonary disease (COPD); anxiety; depression; comorbidities; Patient Health Questionnaire.

\section{Introduction}

Chronic obstructive pulmonary disease (COPD) is a progressive, partially reversible, preventable, and treatable lung disease characterized by longterm breathing problems which typically worsens over time. The main symptoms include shortness 
of breath and cough with sputum production. ${ }^{1}$ Acute exacerbations and frequent comorbidities contribute to the overall severity in individual patients eventually everyday activities, such as walking or getting dressed, become difficult. ${ }^{2,3}$ The prevalence of COPD among Indian males is $5 \%$ and $3.2 \%$ in females. It usually affects over 35 years of age. ${ }^{4}$ Smoking is the most common cause of COPD with factors such as air pollution and genetics playing a minor role. ${ }^{5}$ Long-term exposures to the irritants start an inflammatory response in the lungs resulting in narrowing of the small airways and breakdown of lung tissue. ${ }^{6}$

COPD is a major cause of chronic morbidity and mortality throughout the world and it is the fourth leading cause of death worldwide. ${ }^{7}$ Patients with COPD have chronic respiratory symptoms and significant physical limitations secondary to abnormal pulmonary function. ${ }^{8}$ They often experience depression and anxiety, but little information is available regarding Indian patients with these conditions. The present study assessed depression and anxiety in Indian patients with COPD. There is a well documented association between COPD and anxiety or depression (Dowson et al 20019; Mikkelsen et al 2004 ${ }^{10}$; Kunik et al $2005^{11}$ ). In general practice, there seems to be a relationship between depressionand the severity of the COPD, with $25 \%$ of patients with severe COPD also having depression, $19.6 \%$ of those with mild COPD, and $17.5 \%$ of those in the control group (van Manen et al 2002). ${ }^{12}$

\section{Aiims \& Objectives}

- To assess the association of depression and anxiety in COPD patients

- To correlate between the severity of the anxiety and depression with the severity of the COPD, and

- Compare the above with healthy control subjects

\section{Materials \& Methods}

This is a case control pilot study that was carried out in the outpatient clinic of Chest \& TB
Department, IMCHRC, Indore, M. P. About 30 COPD patients were assessed using Structured Clinical Interview for DSM IV (SCID) for establishing psychiatric diagnosis, Patient Health Questionnaire (PHQ-9) and Beck depression inventory for assessment of the severity of depressive symptoms; Hamilton anxiety scale for the severity of anxiety symptoms, and spirometry for assessing the severity of COPD and were matched to 30 healthy control subjects. Full history taking with concern to duration of the illness, prior admission to intensive care, oxygen therapy or mechanical ventilation was noted. Thorough clinical examination was done. Spirometric assessment was done after administration of adequate dose of short-acting inhaled bronchodilator to minimize variability. Classification of severity of airflow limitation in COPD patients with FEV1/FVC $<0.7$ was done based on post bronchodilator FEV1, according to GOLD 2016. ${ }^{13}$

About 30 healthy subjects with matched age, sex and socioeconomic conditions were recruited as a control group. They were selected from the employees and attendents or relatives of patients coming to the Allergy clinics. Hamilton anxiety scale (HAM-A) ${ }^{14}$ : The HAM-A was developed to measure the severity of anxiety symptoms, and is still widely used today in both clinical and research settings. The scale consists of 14 items, each defined by a series of symptoms, and measures both psychological anxiety (mental agitation and psychological distress) and somatic anxiety (physical complaints related to anxiety). A total score of $0-17$ is considered to be mild, 18-25 moderate, and 26-30 severe. Totals above 30 indicate very severe anxiety. ${ }^{15}$ Beck depression inventory (BDI) measures the depth and behavioral manifestations of depression and consists of 21 items, each of which has four responses of increasing severity. Numerical values from $0-3$ are assigned to each statement to indicate the degree of severity. A total score from $0-9$ is considered normal, 10-16 reflects mild depression, 17-29 reflects moderate depression 
and 30 or above is considered severe depression. It is a widely used standardized instrument. ${ }^{16}$

\section{Exclusion Criteria}

1) Subjects less than 18 years of age

2) Subjects not agreeing to participate

3) Those who are pregnant

4) Suffering from any serious disease such as unstable coronary heart disease, heart failure, advanced kidney or liver failure

5) Any condition resulting in severe learning disability (e.g. brain injury)

6) Those having past history of psychiatric disorders

7) Those unable to comprehend for other reasons will be excluded from the study

\section{Results}

The current study was conducted on 30 COPD patients diagnosed and their level of severity was determined according to GOLD 2014. Thirty healthy age, sex and socio-economic matched subjects were also included in the study as a control group. The demographic descriptive data of both groups are shown in Table 1 .

Table 1: Demographic characteristics among COPD case and healthy subjects $[n=30]$

\begin{tabular}{|l|c|c|}
\hline $\begin{array}{l}\text { AGE } \\
\text { (in Years) }\end{array}$ & $\begin{array}{c}\text { COPD Patients- } \\
\text { Frequency (\%) }\end{array}$ & $\begin{array}{c}\text { Healthy Subjects- } \\
\text { Frequency (\%) }\end{array}$ \\
\hline$<35$ & 0 & $3(10)$ \\
\hline $35-40$ & $1(3.33)$ & $7(23.33)$ \\
\hline $41-45$ & $2(6.67)$ & 0 \\
\hline $46-50$ & $4(13.33)$ & $10(33.33)$ \\
\hline $51-55$ & $3(10)$ & 0 \\
\hline $56-60$ & $7(23.33)$ & $4(13.33)$ \\
\hline $61-65$ & $3(10)$ & $4(13.33)$ \\
\hline $66-70$ & $7(23.33)$ & $2(6.67)$ \\
\hline$>70$ & $3(10)$ & 0 \\
\hline Male & $21(70)$ & $20(66.67)$ \\
\hline Female & $9(30)$ & $10(33.33)$ \\
\hline Smoking Status & & $6(20)$ \\
\hline Yes & $13(43.33)$ & $24(80)$ \\
\hline No & $17(56.67)$ & \\
\hline $\begin{array}{l}\text { Family history } \\
\text { of COPD }\end{array}$ & & $4(13.33)$ \\
\hline Yes & $10(33.33)$ & $26(86.67)$ \\
\hline No & $20(66.67)$ & \\
\hline
\end{tabular}

In the present study $70 \%$ of COPD patients were male. Out of 30 COPD patients 13 (43.33\%) were chronic smokers. There was family history of
COPD in $33.33 \%$ and $13.33 \%$ subjects in case and control group respectively [Table 1].

Table 2: Depression score [PHQ-9] among COPD case and healthy subjects

\begin{tabular}{|l|c|c|}
\hline $\begin{array}{l}\text { PHQ-9 } \\
\text { Score }\end{array}$ & $\begin{array}{c}\text { COPD Patients- } \\
\text { Frequency (\%) }\end{array}$ & $\begin{array}{c}\text { Healthy Subjects- } \\
\text { Frequency (\%) }\end{array}$ \\
\hline 0 & 0 & $15(50)$ \\
\hline $1-5$ & $9(30)$ & $15(50)$ \\
\hline $6-10$ & $8(26.67)$ & 0 \\
\hline $11-15$ & $8(26.67)$ & 0 \\
\hline $16-20$ & $4(13.33)$ & 0 \\
\hline $21-25$ & $1(3.33)$ & 0 \\
\hline
\end{tabular}

Table 2 shows majority of subjects in COPD group was having depression score PHQ-9 (6-10) and (11-15) in $26.67 \%$ respectively. None of control group subject moderate to severe depression scores [Table 2, 3].

Table 3: Level of depression among COPD case and healthy subjects

\begin{tabular}{|l|c|c|}
\hline $\begin{array}{l}\text { Level of } \\
\text { Depression }\end{array}$ & $\begin{array}{c}\text { COPD Patients- } \\
\text { Frequency (\%) }\end{array}$ & $\begin{array}{c}\text { Healthy Subjects- } \\
\text { Frequency (\%) }\end{array}$ \\
\hline None & 0 & $15(50)$ \\
\hline Minimal & $8(26.67)$ & $14(46.67)$ \\
\hline Mild & $9(30)$ & $1(3.33)$ \\
\hline Moderate & $7(23.33)$ & 0 \\
\hline $\begin{array}{l}\text { Moderately } \\
\text { severe }\end{array}$ & $5(16.67)$ & 0 \\
\hline Severe & $1(3.33)$ & 0 \\
\hline
\end{tabular}

Table 4: Anxiety score among COPD case and healthy subjects

\begin{tabular}{|l|c|c|}
\hline $\begin{array}{l}\text { Anxiety } \\
\text { Score }\end{array}$ & $\begin{array}{c}\text { COPD Patients- } \\
\text { Frequency (\%) }\end{array}$ & $\begin{array}{c}\text { Healthy Subjects- } \\
\text { Frequency (\%) }\end{array}$ \\
\hline 0 & 0 & $12(40)$ \\
\hline $1-5$ & 0 & $3(10)$ \\
\hline $5-10$ & $4(13.33)$ & $9(30)$ \\
\hline $11-15$ & $5(16.67)$ & 6 \\
\hline $16-20$ & $8(26.67)$ & 0 \\
\hline $21-25$ & $10(33.33)$ & 0 \\
\hline $26-30$ & $3(10)$ & 0 \\
\hline
\end{tabular}

Table 5: Anxiety level among COPD case and healthy subjects

\begin{tabular}{|l|l|l|}
\hline Anxiety Level & $\begin{array}{l}\text { COPD Patients- } \\
\text { Frequency }(\%)\end{array}$ & $\begin{array}{l}\text { Healthy Subjects- } \\
\text { Frequency }(\%)\end{array}$ \\
\hline None & 0 & $12(40)$ \\
\hline Mild & $13(43.33)$ & $18(60)$ \\
\hline Mild to Moderate & $12(40)$ & 0 \\
\hline Moderate to Severe & $5(16.67)$ & 0 \\
\hline
\end{tabular}

Mild to moderate and moderate to severe anxiety level was observed $40 \%$ and $16.67 \%$ of COPD subjects, whereas none was noted in control group [Table 4, 5]. 
Table 6: Different clinical parameters among COPD case and healthy subjects

\begin{tabular}{|l|c|c|c|c|c|c|c|c|}
\hline \multirow{2}{*}{ Parameters } & \multicolumn{2}{|c|}{ Healthy Control } & \multicolumn{2}{|c|}{ COPD Control } & \multirow{2}{*}{ t Value } & \multirow{2}{*}{ DF } & \multirow{2}{*}{ P value } & \multirow{2}{*}{ Significance } \\
\cline { 2 - 5 } & Mean & SD & Mean & SD & & & & \\
\hline Age & 48.750 & 11.124 & 58.567 & 9.981 & 4.6239 & 29 & $<0.0001$ & HS \\
\hline FEV1 & 91.00 & 3.68 & 71.73 & 11.47 & 8.9014 & 29 & $<0.0001$ & HS \\
\hline Depression Score & 1.47 & 1.66 & 9.70 & 5.63 & 7.7051 & 29 & $<0.0001$ & HS \\
\hline Anxiety Score & 5.20 & 5.07 & 18.50 & 6.03 & 10.7075 & 29 & $<0.0001$ & HS \\
\hline
\end{tabular}

Figure 1: Correlation between age with anxiety and depression scores

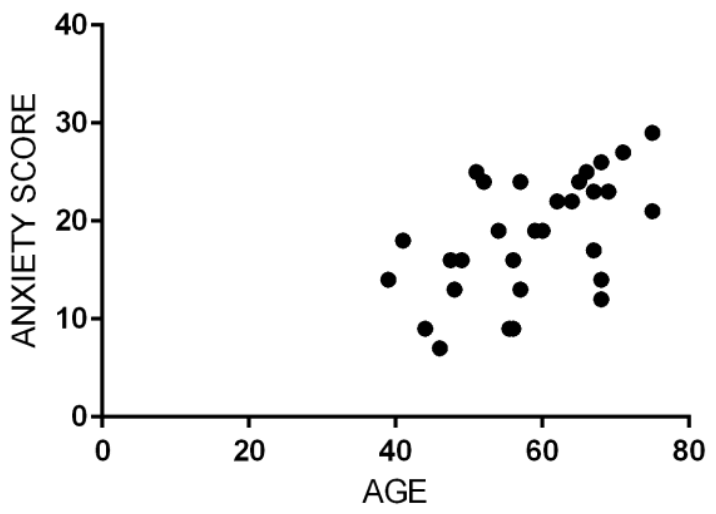

\begin{tabular}{|l|l|}
\hline r value & $\mathbf{0 . 5 3 6}$ \\
\hline $\mathrm{p}$ value & 0.0022 \\
\hline Significance & Significant \\
\hline
\end{tabular}

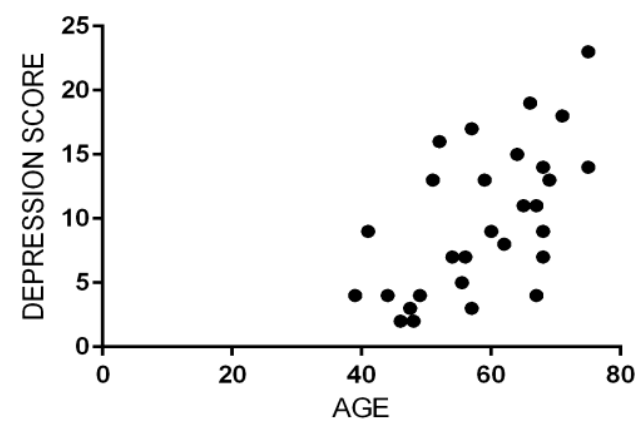

\begin{tabular}{|l|l|}
\hline r value & $\mathbf{0 . 6 0 4}$ \\
\hline$p$ value & 0.0004 \\
\hline Significance & Significant \\
\hline
\end{tabular}

The Fig 1 showed a significant positive $t$ correlation between age and anxiety score and a direct significant correlation was found between $\mathrm{PaO} 2$ and anxiety score. FEV1 showed a significant negative correlation with depression score (Fig. 4). There was no correlation between all personal data of the groups (apart from age) and anxiety or depression scores. Duration of illness showed a significant positive correlation with anxiety and depression score (Fig. 2).
Figure 2: Correlation between duration of illness and anxiety and depression scores

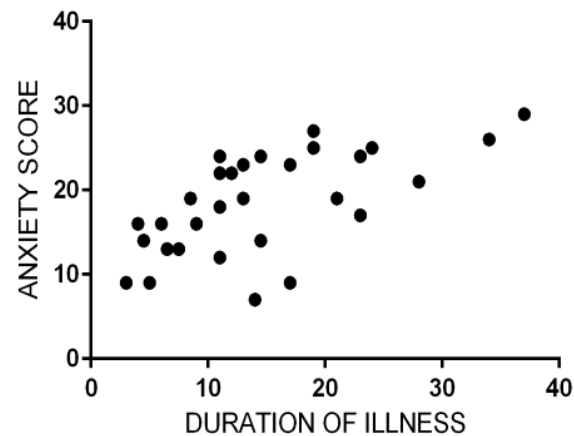

\begin{tabular}{|l|l|}
\hline $\mathbf{r}$ value & $\mathbf{0 . 6 2 4}$ \\
\hline $\mathrm{p}$ value & 0.0002 \\
\hline Significance & Significant \\
\hline
\end{tabular}

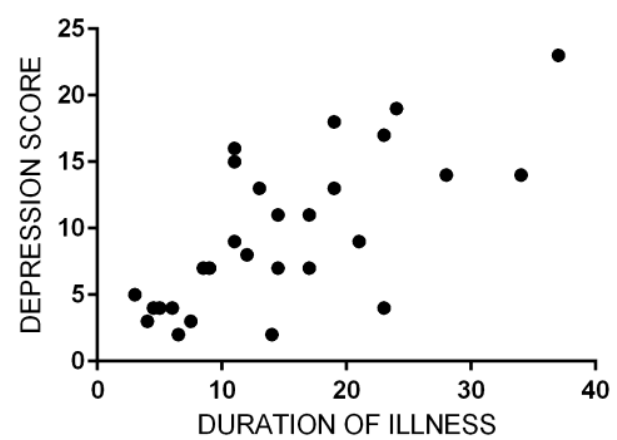

\begin{tabular}{|l|l|}
\hline r value & $\mathbf{0 . 6 9 3}$ \\
\hline $\mathrm{p}$ value & $<0.0001$ \\
\hline Significance & Significant \\
\hline
\end{tabular}


Figure 3: Correlation between duration of smoking and anxiety and depression scores

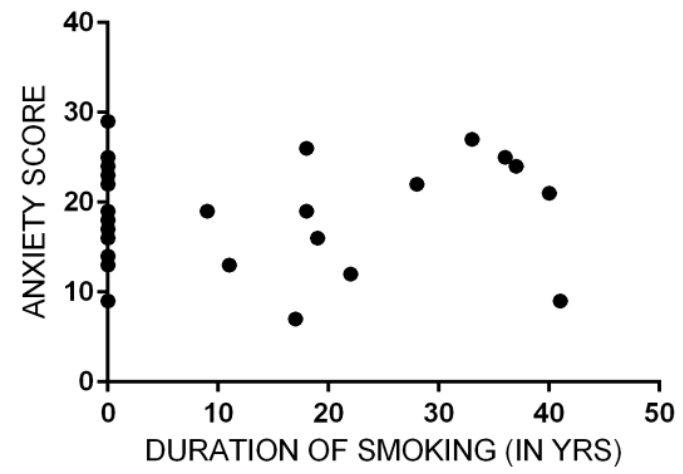

\begin{tabular}{|l|l|}
\hline $\mathbf{r}$ value & $\mathbf{0 . 0 8}$ \\
\hline $\mathrm{p}$ value & 0.6383 \\
\hline Significance & Not Significant \\
\hline
\end{tabular}

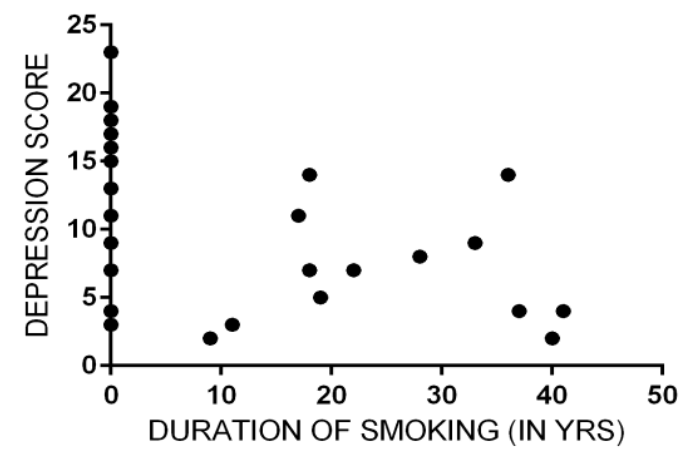

\begin{tabular}{|l|l|}
\hline $\mathbf{r}$ value & $\mathbf{0 . 3 8}$ \\
\hline$p$ value & 0.0379 \\
\hline Significance & Significant \\
\hline
\end{tabular}

There was no correlation was observed between duration of smoking and anxiety and depression scores [Fig. 3].

Figure 4: Correlation between post bronchodilator FEV1 and anxiety and depression scores

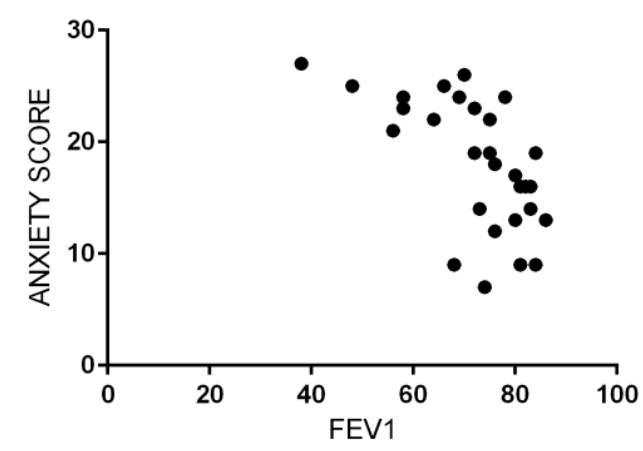

\begin{tabular}{|l|l|}
\hline $\mathbf{r}$ value & $\mathbf{0 . 6 1 3}$ \\
\hline $\mathrm{p}$ value & 0.0004 \\
\hline Significance & Significant \\
\hline
\end{tabular}

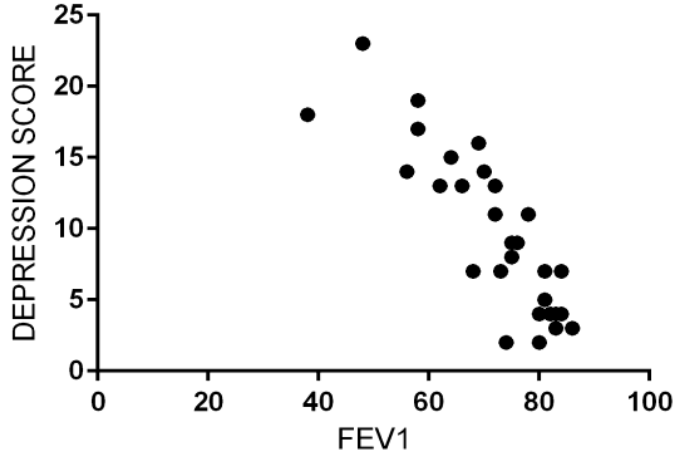

\begin{tabular}{|l|l|}
\hline $\mathbf{r}$ value & $\mathbf{0 . 8 5 3}$ \\
\hline $\mathrm{p}$ value & $<0.0001$ \\
\hline Significance & Significant \\
\hline
\end{tabular}

There was significant negative correlation between post bronchodilator FEV1 and anxiety and depression scores [Fig. 4].

Figure 5: Correlation between severity score and anxiety and depression scores

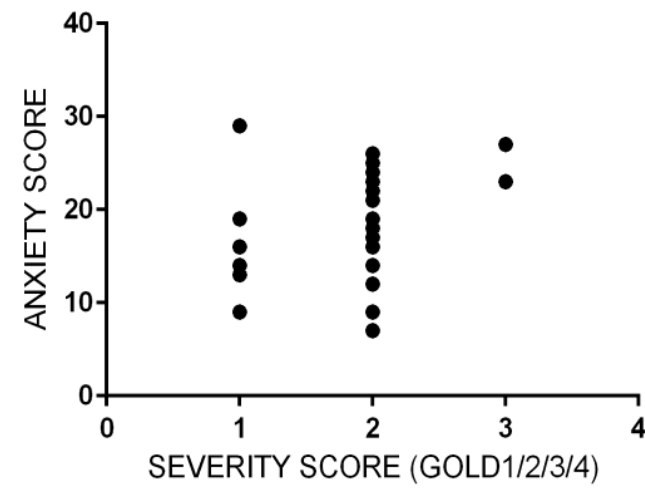

\begin{tabular}{|l|l|}
\hline r value & $\mathbf{0 . 3 1 7}$ \\
\hline $\mathrm{p}$ value & 0.0877 \\
\hline Significance & Not Significant \\
\hline
\end{tabular}

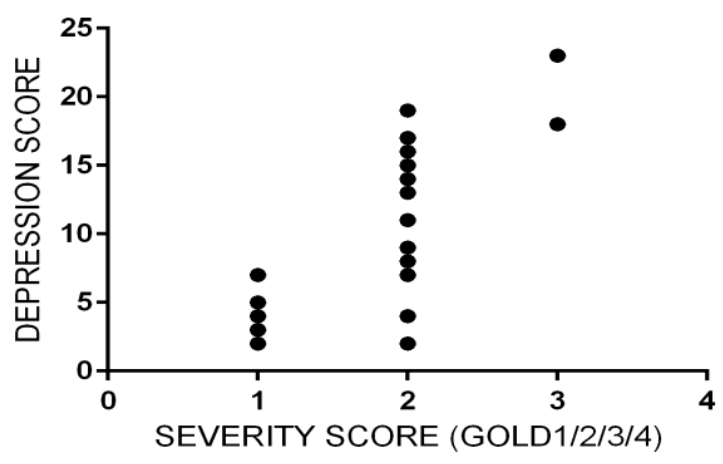

\begin{tabular}{|l|l|}
\hline $\mathbf{r}$ value & $\mathbf{0 . 7 5 2}$ \\
\hline $\mathrm{p}$ value & $<0.0001$ \\
\hline Significance & Significant \\
\hline
\end{tabular}

No correlation between severity score and anxiety and depression scores was observed [Fig. 5]. 
Figure 6: Correlation between duration of illness and severity of COPD

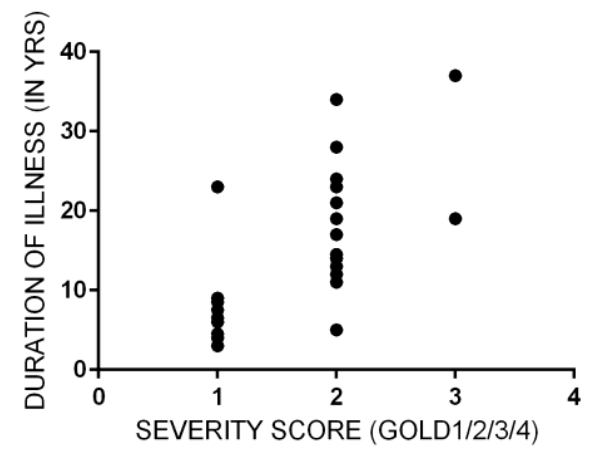

\begin{tabular}{|l|l|}
\hline$r$ value & $\mathbf{0 . 6 1 3}$ \\
\hline$p$ value & $\mathbf{0 . 0 0 0 3}$ \\
\hline Significance & Significant \\
\hline
\end{tabular}

There was a significant correlation between duration of illness and severity of COPD [Fig. 6].

Figure 7: Correlation between duration of smoking and severity of COPD

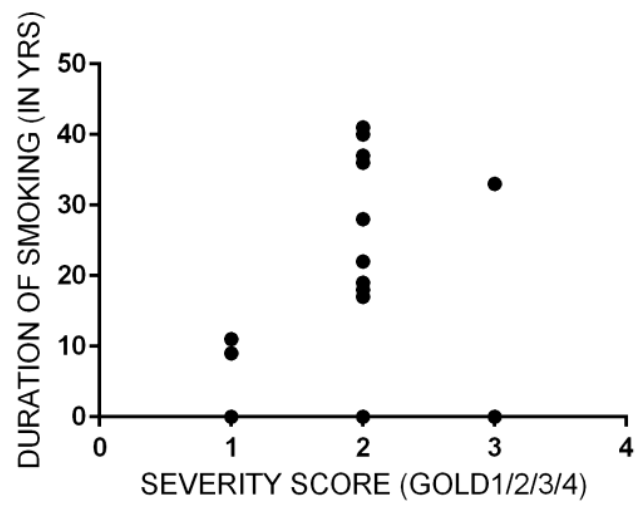

\begin{tabular}{|l|l|}
\hline$r$ value & $\mathbf{0 . 3 7 2}$ \\
\hline$p$ value & $\mathbf{0 . 0 4 2 6}$ \\
\hline Significance & Significant \\
\hline
\end{tabular}

Figure 8: Correlation between post bronchodilator FEV1 and severity of COPD

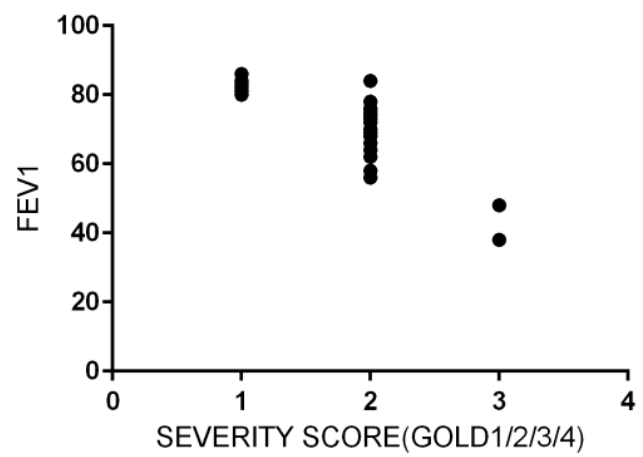

\begin{tabular}{|l|l|}
\hline r value & $\mathbf{0 . 8 0 3}$ \\
\hline $\mathrm{p}$ value & $<\mathbf{0 . 0 0 0 1}$ \\
\hline Significance & Significant \\
\hline
\end{tabular}

\section{Discussion}

Patients with COPD may experience a higher prevalence of psychological distress, like symptoms of anxiety and depression, than the general healthy population. ${ }^{12}$ Increasing evidence suggests that anxiety and depression may have direct impacts on health status, hospitalization and exacerbation of COPD, rather than being consequences or markers of disease severity. Thus, detecting depression or anxiety in patients with COPD is of great importance. ${ }^{17}$ Therefore, the aim of the present study was to assess the symptoms of depression and anxiety in COPD patients and to correlate between the severity of the anxiety and depression with the severity of the COPD.

A recent meta-analysis that included 39,587 individuals with COPD and 39,431 controls found that one in four COPD patients experienced clinically significant depressive symptoms compared with less than one in eight of the controls $(24.6 \%, 95 \%$ confidence interval [CI] 20.0-28.6 versus $11.7 \%$, 95\% CI $9.0-15.1) .{ }^{18}$ These estimates are consistent with the findings of previous qualitative and quantitative reviews that assessed the prevalence of depressive symptoms in COPD. ${ }^{19,20,21}$ Clinical anxiety has also been recognized as a significant problem in COPD, with an estimated prevalence of up to $40 \% .^{22}$ Additionally, COPD patients are ten times more likely to experience panic disorder or panic attacks compared with general population samples. $^{23,24}$ Vineet Mahajan et al 2018 study revealed $32.4 \%$ of patients of COPD had psychiatric co morbidities compared to only $2.9 \%$ of control group which was statistically significant $(\mathrm{p}<0.001){ }^{25}$ In a similar study from North India using MINI as the criteria for diagnosing psychiatric co morbidities, prevalence of psychiatric co morbidities in COPD patients was $28.4 \%$ compared to $2.7 \%$ in controls. $^{26}$

A recent study investigating the prevalence of anxiety and depression in large sample of patients with chronic breathing disorders including COPD, $65 \%$ of COPD patients reported a significant level 
of anxiety and depression on telephone screening and only $31 \%$ were being treated for the same. ${ }^{27}$ Peian Lou et al 2012 study revealed findings confirmed a higher frequency of anxious (18.3\%) and depressive symptoms (35.7\%) in stable COPD patients. Higher percentages of patients with COPD than of controls reported symptoms of depression, while anxiety was also more common in the patients than in the controls. ${ }^{28}$ These high rates stress the importance of screening and treatment of depression and anxiety in patients with COPD to maintain health related quality of life. $^{29}$

The pathophysiology of anxiety and depression among COPD patient is complex and poorly understood. Patients with depression and anxiety are at higher risk of developing COPD due to smoking. Likewise the physical, emotional and social impact of COPD is correlated with development depression and anxiety. This complex interaction between COPD and mental health diseases may cause a self-perpetuating cycle that has a severe impact upon a patient's well-being. ${ }^{30}$ Depression and anxiety symptoms also have significant impact on quality of life and functional status in many chronic diseases. ${ }^{31}$ Comorbid depressive symptoms in patients with COPD are associated with persistent smoking, increased symptom burden, poorer physical and social functioning, and difficulty in performing daily activities. $^{32}$

The present study found a higher prevalence of depressive and anxious symptoms among patients with COPD in India compared to a matched healthy control group without the condition, while the scores for anxious and depressive symptoms were higher among the patients with COPD than among the controls.

\section{Conclusion}

This study confirmed the high prevalence of anxiety and depression in Indian outpatients with COPD. Patients with COPD who had anxiety and/or depression had a poorer health-related quality of life. The severity of anxiety and depression were correlated with the severity of COPD. Anxious and depressive symptoms were also associated with several factors including younger age, female sex, lower household income and history of smoking. Future large scale research to evaluate the effectiveness of novel and integrated care approaches for the management of depression and anxiety in COPD is warranted.

\section{References}

1. Pauwels RA, Buist AS, Calverley PM, Jenkins CR, Hurd SS. Global strategy for the diagnosis, management, and prevention of chronic obstructive pulmonary disease: NHLBI/WHO Global Initiative for Chronic Obstructive Lung Disease (GOLD) Workshop summary. American journal of respiratory and critical care medicine. 2001; 163:1256-76.

2. Dar SA, Bhat BA, Shah NN, Imtiyaz SB. The pattern of psychiatric morbidity in chronic obstructive pulmonary disease: A cross-sectional, Case-Control study from a tertiary care hospital in Kashmir, North India. J Neurosci Rural Pract 2019; 10:6570.

3. Ullah R, Ashraf S. Chronic obstructive lung disease: A rising problem for the world. Pak J Chest Med 2018; 23:130-3.]

4. Jindal SK. COPD: The unrecognized epidemic in India. $\mathbf{J}$ Assoc Physicians India 2012; 60 Suppl: 14-6.

5. Zubair T, Sardar MA. Adequacy of inhaler technique in the patients of copd and asthma. KJMS 2015; 8:221.

6. Rabe KF, Hurd S, Anzueto A, Barnes PJ, Buist SA, Calverley $P$, et al. Global strategy for the diagnosis, management, and prevention of chronic obstructive pulmonary disease: GOLD executive summary. Am J Respir Crit Care Med 2007; 176:532-55.

7. Devine JF. Chronic obstructive pulmonary disease: an overview. Am Health Drug Benefits. 2008;1(7):34-42. 
8. Rossi A, Butorac-Petanjek B, Chilosi M, et al. Chronic obstructive pulmonary disease with mild airflow limitation: current knowledge and proposal for future research - a consensus document from six scientific societies. Int J Chron Obstruct Pulmon Dis. 2017; 12:2593-2610.

9. Dowson C, Laing R, Barraclough R, et al. The use of the Hospital Anxiety and Depression Scale (HADS) in patients with chronic obstructive pulmonary disease: a pilot study. N Z Med J. 2001; 114:447-9.

10. Mikkelsen RL, Middelboe T, Pisinger C, et al. Anxiety and depression in patients with chronic obstructive pulmonary disease (COPD). A review. Nord J Psychiatry. 2004;58:65-70.

11. Kunik ME, Roundy K, Veazey C, et al. Surprisingly high prevalence of anxiety and depression in chronic breathing disorders. Chest. 2005; 127:1205-11.

12. van Manen JG, Bindels PJ, Dekker FW, et al. Risk of depression in patients with chronic obstructive pulmonary disease and its determinants. Thorax. 2002; 57:412-16.

13. Global strategy for diagnosis, management, and prevention of COPD $2016 . \quad$ Available at: https://goldcopd.org/global-strategydiagnosis-management-prevention-copd2016/ [Accessed on 28 ${ }^{\text {th }}$ December 2018].

14. W. Maier, R. Buller, M. Philipp, I. Heuser, The Hamilton anxiety scale: reliability, validity and sensitivity to change in anxiety and depressive disorders, J. Affect. Disord. 1988; 14 (1):61-68.

15. Elassal G, Elsheikh M, Abu Zeid AG. Assessment of depression and anxiety symptoms in chronic obstructive pulmonary disease patients:A case-control study. Egyptian Journal of Chest Diseases and Tuberculosis (2014); 63: 575-582.

16. Beck A, Ward C, Mendelson M. Beck depression inventory (BDI). Arch. Gen. Psychiatry 1961; 4: 561-571.
17. $\mathrm{Xu} \mathrm{W,} \mathrm{Collet} \mathrm{JP,} \mathrm{Shapiro} \mathrm{S,} \mathrm{et} \mathrm{al.}$ Independent effect of depression and anxiety on chronic obstructive pulmonary disease exacerbations and hospitalizations, Am. J. Respir. Crit. Care Med. 2008; 178 (9): 913-920.

18. Zhang MW, Ho RC, Cheung MW, Fu E, Mak A. Prevalence of depressive symptoms in patients with chronic obstructive pulmonary disease: a systematic review, meta-analysis and meta-regression. Gen Hosp Psychiatry. 2011; 33(3):217-223.

19. van Ede L, Yzermans CJ, Brouwer HJ. Prevalence of depression in patients with chronic obstructive pulmonary disease: a systematic review. Thorax. 1999;54(8):688-692.

20. Mannino DM, Buist AS. Global burden of COPD: risk factors, prevalence, and future trends. Lancet. 2007; 370(9589):765-773.

21. Kunik ME, Roundy K, Veazey C, et al. Surprisingly high prevalence of anxiety and depression in chronic breathing disorders. Chest. 2005; 127(4):1205-1211.

22. Willgoss TG, Yohannes AM. Anxiety disorders in patients with COPD: a systematic review. Respir Care. 2013; 58(5):858-866.

23. Livermore N, Sharpe L, McKenzie D. Panic attacks and panic disorder in chronic obstructive pulmonary disease: a cognitive behavioural perspective. Respir Med. 2010; 104(9):1246-1253.

24. Panagioti M, Scott C, Blakemore A, Coventry PA. Overview of the prevalence, impact, and management of depression and anxiety in chronic obstructive pulmonary disease. Int J Chron Obstruct Pulmon Dis. 2014 Nov 13; 9:1289-306.

25. Mahajan V, Sareen H, Kant S, Bajpai J, Narain A, Soni S, et al. Prevalence of psychiatric co morbidities in bronchial asthma and chronic obstructive pulmonary 
disease patients in North India population cohort. Int J Res Med Sci 2018; 6:2143-7.

26. Chaudhary SC, Nanda S, Tripathi A, Sawlani KK, Gupta KK, Himanshu D, et al. Prevalence of psychiatric co morbidities in chronic obstructive pulmonary disease patients. Lung India. 2016; 33:174-8.

27. Kunik ME, Roundy K, Veazey C, Souchek J, Richardson P, Wray NP, et al. Surprisingly high prevalence of anxiety and depression in chronic breathing disorders. Chest. 2005; 127:1205-11.

28. Lou P, Zhu Y, Chen P, Zhang P, Yu J, Zhang N, et al. Prevalence and correlations with depression, anxiety, and other features in outpatients with chro nic obstructive pulmonary disease in China : a cross-sectional case control study. BMC Pulm Med. 2012 Sep 10; 12:53.

29. Cleland JA, Lee AJ, Hall S: Associations of depression and anxiety with gender, age, health-related quality of life and symptoms in primary care COPD patients. Fam Pract 2007, 24:217-223.

30. Pumar MI, Gray CR, Walsh JR, Yang IA, Rolls TA, Ward DL. Anxiety and depression-Important psychological comorbidities of COPD. J Thorac Dis. 2014 Nov;6(11):1615-31.

31. Yohannes AM, Willgoss TG, Baldwin RC, et al. Depression and anxiety in chronic heart failure and chronic obstructive pulmonary disease: prevalence, relevance, clinical implications and management principles. Int J Geriatr Psychiatry 2010; 25:1209-21.

32. Beck JG, Scott SK, Teague RB, et al. Correlates of daily impairment in COPD. Rehabilitation Psychology 1988; 33:77-84. 